\begin{abstract}
Iranica
Abstracta Iranica Revue bibliographique pour le domaine irano-aryen

Volume 34-35-36 | 2017

Comptes rendus des publications de 2011-2013
\end{abstract}

\title{
Mark A. Christian, Rüdiger Schmitt (eds.). Permutations of Astarte
}

\section{Astrid Nunn}

\section{(2) OpenEdition}

1 Journals

\section{Édition électronique}

URL : http://journals.openedition.org/abstractairanica/41205

DOI : 10.4000/abstractairanica.41205

ISSN : 1961-960X

Éditeur :

CNRS (UMR 7528 Mondes iraniens et indiens), Éditions de l'IFRI

Référence électronique

Astrid Nunn, «Mark A. Christian, Rüdiger Schmitt (eds.). Permutations of Astarte », Abstracta Iranica [En ligne], Volume 34-35-36 | 2017, document 92, mis en ligne le 15 juillet 2016, consulté le 28 septembre 2020. URL : http://journals.openedition.org/abstractairanica/41205 ; DOI : https://doi.org/10.4000/ abstractairanica.41205

Ce document a été généré automatiquement le 28 septembre 2020.

Tous droits réservés 


\title{
Mark A. Christian, Rüdiger Schmitt (eds.). Permutations of Astarte
}

\author{
Astrid Nunn
}

\section{RÉFÉRENCE}

Mark A. Christian, Rüdiger Schmitt (eds.). Permutations of Astarte. 2013. (Die Welt des Orients 43/2)

1 Le vol. 43/2 de la revue WO est la publication d'une rencontre qui a eu lieu à Amsterdam en 2012 dans le cadre du programme ERI (Expressions of Religion in Israel). Les participants ont étudié les changements et les "avatars" d'Astarté dans les religions méditerranéennes du second et premier millénaire. Astarté est bien documentée au Levant dès le III $^{\mathrm{e}}$ mill. (Ebla et Mari), puis au second mill. à Emar et Ugarit. Les participants se sont intéressés à la répercussion de la multiplication des cultes dans une aire géographique élargie sur la personnalité d'Astarté au I ${ }^{\mathrm{er}}$ mill. av. J.-C.

\section{AUTEURS}

\section{ASTRID NUNN}

Université de Munich 